\title{
A novel green one-step synthesis of silver nanoparticles using chitosan: catalytic activity and antimicrobial studies
}

\author{
Maragoni Venkatesham • Dasari Ayodhya $\cdot$ \\ Alle Madhusudhan • Nagati Veera Babu • \\ Guttena Veerabhadram
}

Received: 19 October 2012/ Accepted: 22 November 2012/Published online: 16 December 2012

(C) The Author(s) 2012. This article is published with open access at Springerlink.com

\begin{abstract}
Stable silver nanoparticles were synthesized using chitosan acting as both reducing and stabilizing agent without using any toxic chemicals. This reaction was carried out in an autoclave at a pressure of $15 \mathrm{psi}$ and $120^{\circ} \mathrm{C}$ temperature by varying the time. The influence of different parameters such as time, change of concentration of silver nitrate and concentration of chitosan on the formation of silver nanoparticles were studied. The synthesized silver nanoparticles were characterized by UV-visible spectroscopy, Fourier transform infrared, X-ray diffraction and transmission electron microscopy. The results of catalytic reduction of 4-nitrophenol by sodium borohydride in the presence of green synthesized silver nanoparticles were presented. The antimicrobial activity of silver nanoparticles was tested against Escherichia coli and Micrococcus luteus and was found to be possessing inhibiting property.
\end{abstract}

Keywords Green synthesis - Chitosan - Autoclave ·

Nanosilver - Catalysis and antimicrobial activity

\section{Introduction}

Metallic nanoparticles have been widely studied in recent years because of their potential use as catalysts (Chimentao et al. 2004; Gong and Mullins 2009; Campelo et al. 2009; $\mathrm{Li}$ et al. 2010). Silver nanoparticles are of particular

M. Venkatesham - D. Ayodhya · A. Madhusudhan .

G. Veerabhadram ( $\square)$

Department of Chemistry, Osmania University,

Hyderabad 500007, India

e-mail: gvbhadram@gmail.com

N. Veera Babu

Department of Biochemistry, Osmania University,

Hyderabad 500007, India interesting due to their role as substrates in the studies of catalysis (Tsujino and Matsumura 2005; Shimizu et al. 2010), surface enhancement, Raman spectroscopy (Debarre et al. 2004; Terekhov et al. 2011) and in the biomedical field (Xu et al. 2006; Liu et al. 2010; Krishna Rao et al. 2012). Because of their vast applications in various fields, many techniques of synthesizing silver nanoparticles have been investigated and some of them are: chemical reduction (Bhui and Misra 2012), electrochemical reduction (Starowicz et al. 2006; Hosseini and Momeni 2010), photochemical reduction (Kutsenko and Granchak 2009), microemulsion (Zhang et al. 2011), gamma-ray irradiation (Huang et al. 2009; Rao et al. 2010), UV irradiation (Spadaro et al. 2010), ultrasonic method (Byeon and Kim 2012), microwave method (Nadagouda et al. 2011), etc. Different varieties of stabilizers have been used in silver nanoparticles preparation, as mentioned above, to achieve the best control of size, distribution, shape, stability and solubility of silver nanoparticles. The most commonly used stabilizers are polyvinyl pyrrolidone (PVP) (Link et al. 1999; Tan et al. 2003), polyvinyl alcohol (PVA) (Abdul kareem and Anu kaliani 2011), polyaniline (Bouazza et al. 2009) and polyethylene glycol (PEG) (Tan et al. 2003). Natural polymers have also been used in the preparation of nanosilver because they are nontoxic and biocompatible. Starch (Hu et al. 2008) and chitosan (Hettiarachchi and Wickramarachchi 2011) have been used as stabilizers for the preparation of metal nanoparticles. Many of the nanoparticle synthesis methods, however, involve use of hazardous chemicals, low material conversions and high energy requirements. Over past decade, keen interest has been evinced in green synthesis. Green synthesis is costeffective, environment friendly, easily scaled up for largescale synthesis and also there is no need to use toxic chemicals. 
Chitosan is a biodegradable polysaccharide copolymer of $N$-acetyl-D-glucosamine and D-glucosamine, obtained by the alkaline deacetylation of chitin (Onishi and Machida 1999). It is considered as a nontoxic, biodegradable, biocompatible and environmental-friendly material with many superior properties (Jigar and Sinha 2007). It is the second most plentiful natural biopolymer and is relatively cheap (Ma et al. 2008). In this paper, we report the green synthesis of silver nanoparticles using chitosan as both reducing and stabilizing agent and without using any toxic chemicals. This reaction is carried out in an autoclave at a pressure of $15 \mathrm{psi}$ and at $120^{\circ} \mathrm{C}$ temperature by varying the time. The influence of different parameters such as time, change of concentration of silver nitrate and concentration of chitosan on the formation of silver nanoparticles was studied.

In recent days, nitro aromatic compounds are widely used in chemical industries. These are xenobiotics, used in manufacturing of pesticides, dyes, plasticizers, fungicides and explosives. These anthropogenic compounds are highly hazardous when released in the environment. In particular, 4-nitrophenol has been listed as priority pollutant by the US Environmental Protection Agency (EPA) because of its higher solubility and stability in water. 4-nitrophenol stays a longer time in water and surface soil without degradation and gets accumulated in deep soil indefinitely (Pocurull et al. 1996). In the present study, we report the catalytic activity of green synthesized silver nanoparticles toward 4-nitrophenol reduction and microbial activity toward Gram-positive and Gram-negative bacteria.

\section{Experimental}

\section{Materials}

Chitosan, $\mathrm{MW} \approx 70,000$ and $>80 \%$ deacetylated, was purchased from India Sea Foods, Kochi, India. Acetic acid, 4-nitrophenol, sodium chloride, silver nitrate and sodium borohydride were obtained from S D Fine-chem Limited, Mumbai, India. The test strains, Escherichia coli MTCC 1303 and Micrococcus luteus MTCC 2987, were purchased from IMTECH, Chandigarh, India. Yeast extract, tryptophan and bacterial-grade agar-agar were purchased from Himedia Laboratories, Mumbai, India.

Preparation of silver nanoparticles

Chitosan $(0.5 \%)$ solution was prepared by dissolving chitosan $(0.5 \mathrm{~g})$ in acetic acid $(100 \mathrm{ml}, 2 \%)$ solution and also silver nitrate $(0.5 \mathrm{~g})$ in deionized water $(100 \mathrm{ml})$. Chitosan $(5 \mathrm{ml}, 0.5 \%)$ solution was mixed with silver nitrate $(5 \mathrm{ml}, 0.5 \%)$ solution in a boiling tube. This mixture was kept in autoclave at 15 psi pressure, at $120^{\circ} \mathrm{C}$ for different time intervals. The resulting solution was clear yellow in color indicating the formation of silver nanoparticles. Studies were made varying the concentration of silver nitrate $(0.1-0.5 \%)$, keeping the concentration of chitosan $(0.5 \%)$ constant, and also varying the concentration of chitosan (0.1-0.5\%), keeping silver nitrate $(0.5 \%)$ concentration constant.

\section{Characterizations}

The silver nanoparticles, stabilized in chitosan solution, were analyzed by UV-vis absorbance spectroscopy. UVvis spectroscopic measurements were made at room temperature using a Shimadzu dual beam UV-vis spectrophotometer, Japan. Fourier transform infrared (FTIR) spectra of silver nanoparticles stabilized in chitosan and chitosan alone were recorded in $\mathrm{KBr}$ pellets using an FTIR spectrophotometer (Bruker Optics, Germany). The scan was performed in the range $400-4,000 \mathrm{~cm}^{-1}$. X-ray diffraction (XRD) measurement of silver nanoparticles stabilized in chitosan was carried out on X'pert Pro X-ray diffractometer (Panalytical B.V., Netherlands) operating at $40 \mathrm{kV}$ and a current of $30 \mathrm{~mA}$ at a scan rate of $0.388 \mathrm{~min}^{-1}$. The size distribution and crystallinity of the silver nanoparticles stabilized in chitosan were obtained by high-resolution transmission electron microscopy (HRTEM) measurement, casting nanoparticle dispersion on carbon-coated copper grids and allowing drying at room temperature. Measurements were done on Tecnai $\mathrm{G}^{2}$ F30 S-Twin instrument (FEI Company, USA) operated at an accelerating voltage of $200 \mathrm{kV}$ with a lattice resolution of $0.14 \mathrm{~nm}$ and point image resolution of $0.20 \mathrm{~nm}$.

\section{Catalytic activity}

To a $3 \mathrm{ml}$ cuvette containing freshly prepared sodium borohydride $(1 \mathrm{ml}, 0.2 \mathrm{M})$ solution, 4-nitrophenol $(1.9 \mathrm{ml}$, $0.2 \mathrm{mM}$ ) solution was added. The cuvette was then placed in a UV-vis spectrophotometer and the absorbance against wavelengths recorded. After adding silver nanoparticles stabilized in chitosan $(0.1 \mathrm{ml}, 0.1 \%)$ solution, the cuvette was shaken vigorously for mixing and kept in a UV-vis spectrophotometer.

Antibacterial property of samples

Luria-Bertani (LB) agar medium was prepared by adding yeast extract $(0.5 \mathrm{~g})$, tryptophan $(1 \mathrm{~g})$, sodium chloride $(1 \mathrm{~g})$ and bacterial grade agar $(2.5 \mathrm{~g})$ in distilled water $(100 \mathrm{ml})$. Then the agar medium was sterilized by autoclaving at a pressure of $15 \mathrm{psi}$ and $120{ }^{\circ} \mathrm{C}$ temperature for $30 \mathrm{~min}$. This medium was transferred into sterilized Petri dishes in a 
laminar air flow. After solidification of the media, overnight culture of E. coli $(100 \mu \mathrm{l})$ and M. luteus $(100 \mu \mathrm{l})$ was spread separately on the solid surface of the media. Sterile discs were kept on these inoculated plates with the help of sterile forceps. Sample $(10 \mu \mathrm{l})$ solutions were placed on these discs and were incubated at $37{ }^{\circ} \mathrm{C}$ for $24 \mathrm{~h}$ in a bacterial incubator. The inhibition zone that appeared around the disc was measured and recorded as the antibacterial effect of chitosan and the nanosilver stabilized in chitosan.

\section{Results and discussion}

UV-visible spectroscopy analysis

UV-visible absorption spectra recorded is quite sensitive to the formation of silver nanoparticles because of the fact that silver nanoparticles exhibit an intense absorption peak due to surface plasmon resonance (SPR). Figures 1 and 2 show the UV-vis spectra of silver nanoparticles prepared with different concentrations of chitosan and silver nitrate. All spectra exhibit an absorption band in the range of 410-430 nm, a typical plasmon resonance band of silver nanoparticles. There are no peaks located around 335 and $560 \mathrm{~nm}$, indicating the absence of nanoparticle aggregation. The reduction was studied with silver nitrate $(0.5 \%)$ and chitosan $(0.5 \%)$ by varying the time (10-60 $\mathrm{min})$. The absorption against wavelength curves at various times is given in Fig. 3. It was noticed that the reduction capacity of chitosan increased with time. As the autoclaving time increases, possibly more and more of hydroxyl groups are converted to carbonyl groups by air oxidation, which in turn reduces the silver ions. A single strong peak with a maximum around $420 \mathrm{~nm}$ was observed in the UV-vis spectra, which corresponds to typical SPR of conducting electrons from the surface of silver nanoparticles. Figure 1 shows the UV-vis spectra of the silver nanoparticles prepared with different concentrations of silver nitrate $(0.1-0.5 \%)$ with chitosan $(0.5 \%)$ and $50 \mathrm{~min}$ of autoclaving. The efficiency of nanoparticle synthesis increases with increase in the concentration of silver nitrate, due to an enhancement in the oxidation of hydroxyl groups of chitosan by silver ions. Further, the production of nanoparticles from silver nitrate $(0.5 \%)$ was monitored with varying concentrations of chitosan $(0.1-0.5 \%)$ for $50 \mathrm{~min}$ of reaction time and their respective spectra are depicted in Fig. 2. The intensity of the absorption of the solutions increased with increase in the concentration of chitosan.

Fourier transform infrared spectroscopy analysis

Figure 4 shows the FTIR spectrum of chitosan and silver nanoparticles stabilized in chitosan. The IR spectrum of

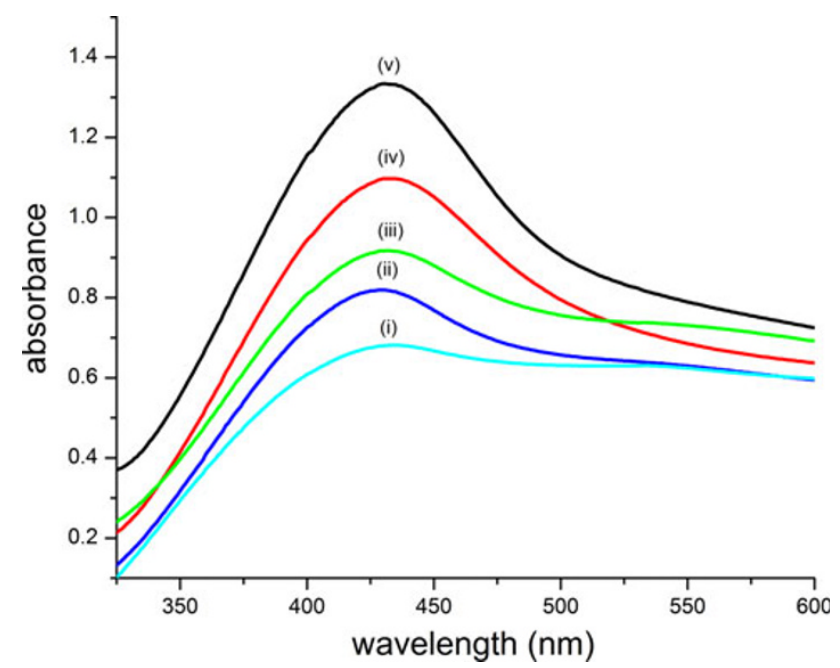

Fig. 1 UV-visible absorption spectra of silver nanoparticles stabilized in chitosan using various concentrations of $(i)$ silver nitrate $(0.1 \%)$, (ii) silver nitrate $(0.2 \%)$, (iii) silver nitrate $(0.3 \%)$, (iv) silver nitrate $(0.4 \%)$ and $(v)$ silver nitrate $(0.5 \%)$ at chitosan $(0.5 \%)$ and $50 \mathrm{~min}$ of autoclaving

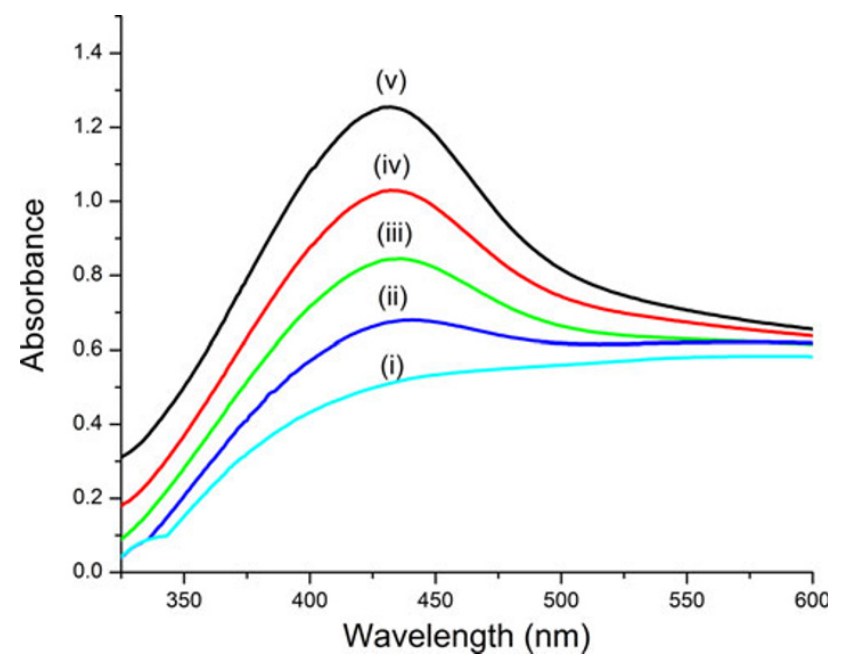

Fig. 2 UV-visible absorption spectra of silver nanoparticles stabilized in chitosan using various concentrations of $(i)$ chitosan $(0.1 \%)$, (ii) chitosan $(0.2 \%)$, (iii) chitosan $(0.3 \%)$, (iv) chitosan $(0.4 \%)$ and (v) chitosan $(0.5 \%)$ at silver nitrate $(0.5 \%)$ and $50 \mathrm{~min}$ of autoclaving

chitosan absorption bands at 3,447 and $2,881 \mathrm{~cm}^{-1}$ represent the $-\mathrm{NH}_{2},-\mathrm{OH}$ and $-\mathrm{CH}_{2}$, and $-\mathrm{CH}_{3}$ aliphatic groups. Absorption bands at $1,600 \mathrm{~cm}^{-1}$ represent the amino group bending vibrations and $1,422 \mathrm{~cm}^{-1}$ of the $-\mathrm{OH}$ group of the primary alcoholic group. The amino group has a characteristic absorption band in the region of $3,400-3,500 \mathrm{~cm}^{-1}$, which is masked by the broad spectrum band from the $-\mathrm{OH}$ group. The absorption band at $1,657 \mathrm{~cm}^{-1}$ is attributed to the $-\mathrm{CONH}_{2}$ group of chitosan. In the FTIR spectrum of silver nanoparticle stabilized in chitosan, the absorption bands at $1,657 \mathrm{~cm}^{-1}$ and $1,600 \mathrm{~cm}^{-1}$, representing chitosan

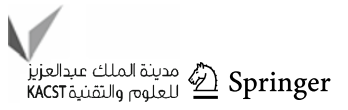




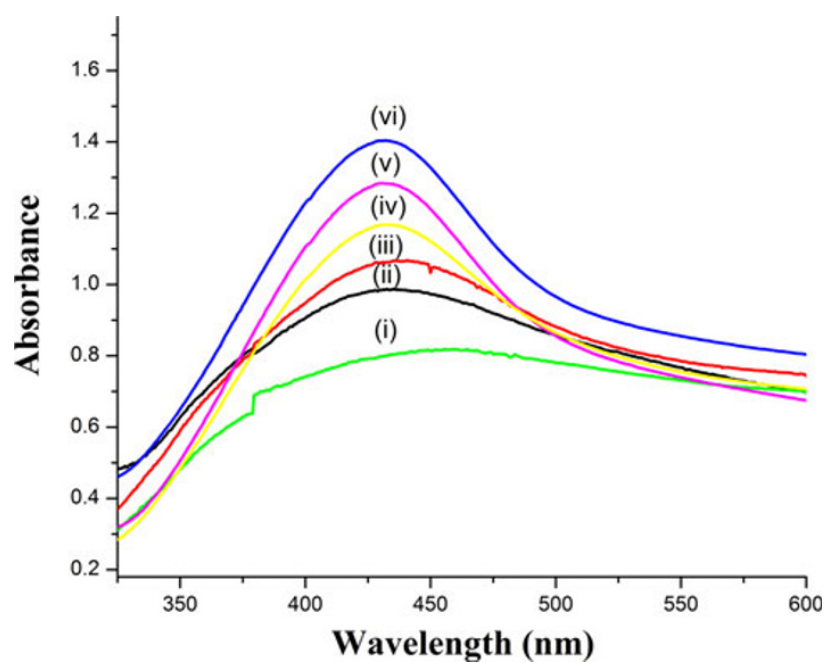

Fig. 3 UV-visible absorption spectra of silver nanoparticles stabilized in chitosan by varying the time: (i) $10 \mathrm{~min}$, (ii) $20 \mathrm{~min}$, (iii) $30 \mathrm{~min}$, (iv) $40 \mathrm{~min}$, (v) $50 \mathrm{~min}$ and (vi) $60 \mathrm{~min}$

$-\mathrm{CONH}_{2}$ and $-\mathrm{NH}_{2}$ groups, disappeared and a new band appeared at $1,635 \mathrm{~cm}^{-1}$, which indicated the attachment of silver to nitrogen atom. The variation in the shape and peak positions of the $-\mathrm{NH}_{2}$ and $-\mathrm{OH}$ at $3,447 \mathrm{~cm}^{-1}$ occurred because of contribution toward the reduction and stabilization process.

\section{$\mathrm{X}$-Ray diffraction analysis of silver nanoparticles}

The XRD technique was used to determine the crystal structure of green synthesized silver nanoparticles. Figure 5 displays the XRD pattern of the presently synthesized silver nanoparticles. A number of Brag reflections with $2 \theta$ values of $38.25,43.95,64.5$ and 77.21 corresponding to the

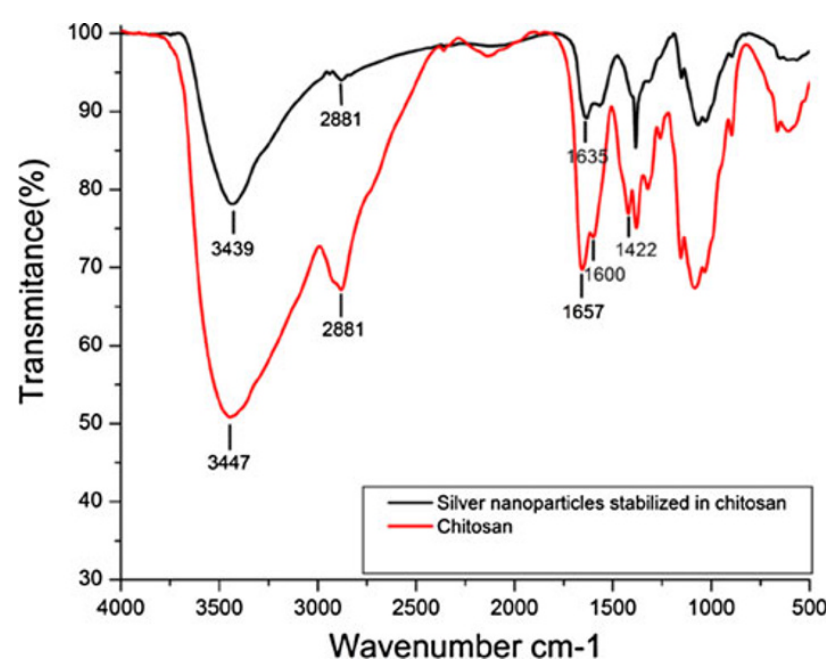

Fig. 4 FTIR spectra of silver nanoparticles stabilized in chitosan and pure chitosan
(111), (200), (220) and (311) sets of lattice planes, respectively, are observed and shown in Table 1 , which may be indexed as the band for face centered cubic (fcc) structure of silver nanoparticles. The peak corresponding to the (111) plane is more intense than the other planes. The broadening of these peaks is mostly due to the effect of nano-sized particles.

Transmission electron microscopy (TEM) analysis of silver nanoparticles stabilized in chitosan

A typical TEM image of silver nanoparticles formed is displayed in Fig. 6. The silver nanoparticles are well distributed in the chitosan matrix. More than $70 \%$ of the particles are in the size range from 5 to $15 \mathrm{~nm}$ and very few particles are also observed above the $30 \mathrm{~nm}$ range. Figure 6 inset shows the SAED pattern of silver nanoparticles stabilized in chitosan, exhibiting polycrystalline diffraction rings, which can be indexed to cubic-phase metal silver, indicating that these nanoparticles are crystalline metallic silver.

\section{Catalytic activity}

The catalytic activity of green synthesized silver nanoparticles stabilized in chitosan was investigated, using the reduction of 4-nitrophenol to 4-aminophenol by sodium borohydride as a model reaction. To a $3 \mathrm{ml}$ cuvette containing freshly prepared sodium borohydride ( $1 \mathrm{ml}, 0.2 \mathrm{M})$ solution, 4-nitrophenol (1.9 ml, $0.2 \mathrm{mM})$ solution was added. The cuvette was then placed in a UV-vis spectrophotometer. UV-vis absorption spectra of the reduction of 4-nitrophenol catalyzed by silver nanoparticles stabilized in chitosan is shown in Fig. 7. The 4-nitrophenol is stable

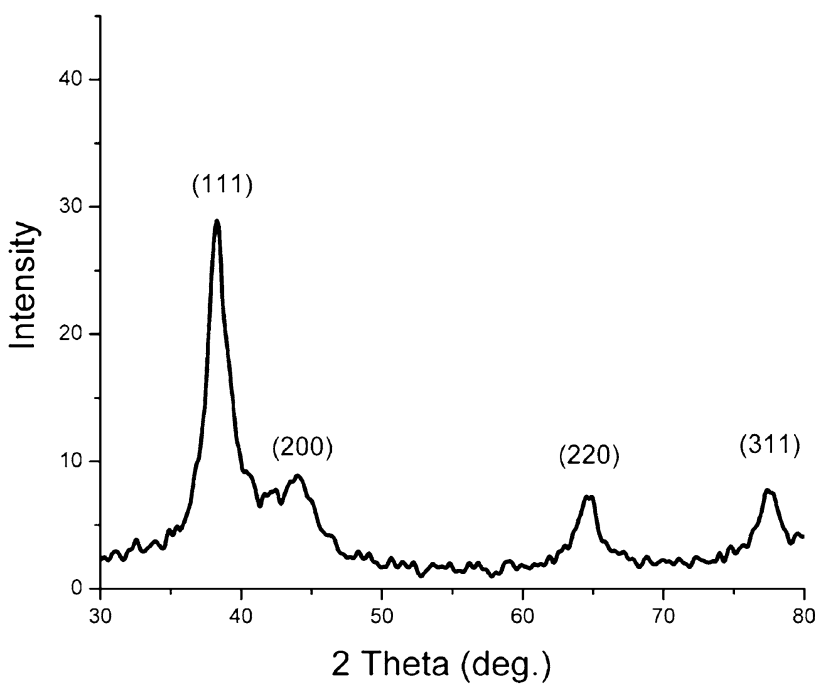

Fig. 5 Typical XRD pattern of the silver nanoparticles stabilized in chitosan 
Table 1 X-ray diffraction peak list of silver nanoparticles

\begin{tabular}{lcllc}
\hline Pos. $\left({ }^{\circ} 2 \theta\right)$ & Height $(\mathrm{cm})$ & FWHM $\left({ }^{\circ} 2 \theta\right)$ & d-spacing $(\AA)$ & Rel. Int. $(\%)$ \\
\hline 38.2522 & 17.89 & 0.9600 & 2.35099 & 100.00 \\
43.9478 & 1.00 & 0.4734 & 2.06032 & 5.59 \\
64.3169 & 1.00 & 0.3125 & 1.44841 & 5.59 \\
77.2100 & 2.00 & 0.3367 & 1.23558 & 11.18 \\
\hline
\end{tabular}

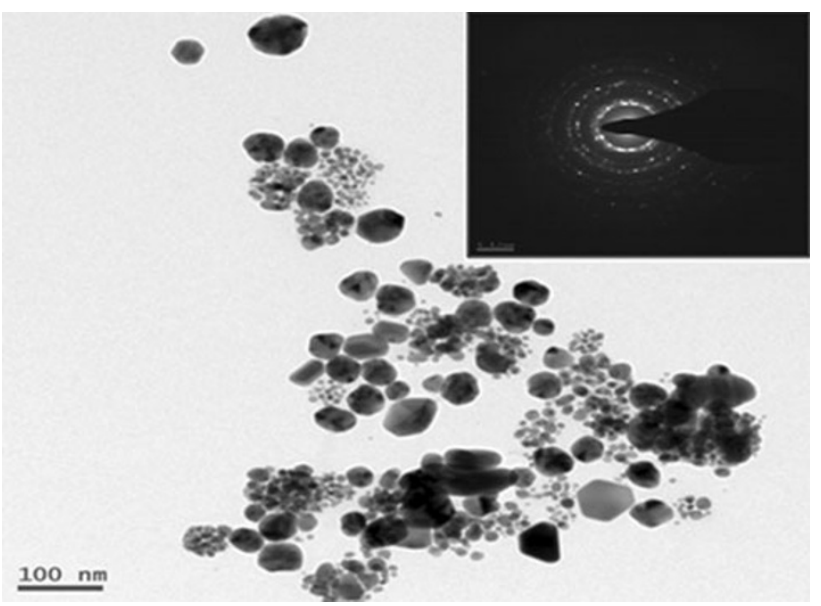

Fig. 6 Typical TEM image of silver nanoparticles in stabilized in chitosan. Inset shows the SAED pattern of the silver nanoparticles

and stays a longer time in water. An aqueous solution of 4-aminophenol shows absorption maximum at $297 \mathrm{~nm}$ in UV-vis spectra. An aqueous solution of 4-nitrophenol shows a distinct spectral profile with absorption maximum at $317 \mathrm{~nm}$, which shifts to $400 \mathrm{~nm}$ in the presence of sodium borohydride due to the formation of the 4-nitrophenolate ion (Pradhan et al. 2001). The anionic silver species remain stable for weeks in the absence of any other reagent. After adding nanoparticles stabilized in chitosan $(0.1 \mathrm{ml}, 0.1 \%)$ solution, the cuvette was shaken vigorously for mixing and kept in UV-vis spectrophotometer. The peak at $400 \mathrm{~nm}$ disappeared, and a new peak at $297 \mathrm{~nm}$ appeared, which is known to be due to absorption of 4-aminophenol (Panigrahi et al. 2007).

The concentration of the sodium borohydride greatly exceeds that of 4-nitrophenol and the catalyst nanoparticles. The excess of sodium borohydride used increases the $\mathrm{pH}$ of the reacting system, thereby retarding the degradation of the borohydride ions, and the liberated hydrogen is purged out, thereby checking the aerial oxidation of the reduced product of 4-nitrophenol. It is well known that the metal nanoparticles catalyze this reaction by facilitating electron relay from the donor $\mathrm{BH}_{4}{ }^{-}$to acceptor 4-nitrophenol to overcome the kinetic barrier. The catalytic reduction proceeds on the surface of the metal nanoparticles. As soon as the electron donor $\left(\mathrm{BH}_{4}{ }^{-}\right)$and electron acceptor (4-nitrophenolate ion) are adsorbed on the surface

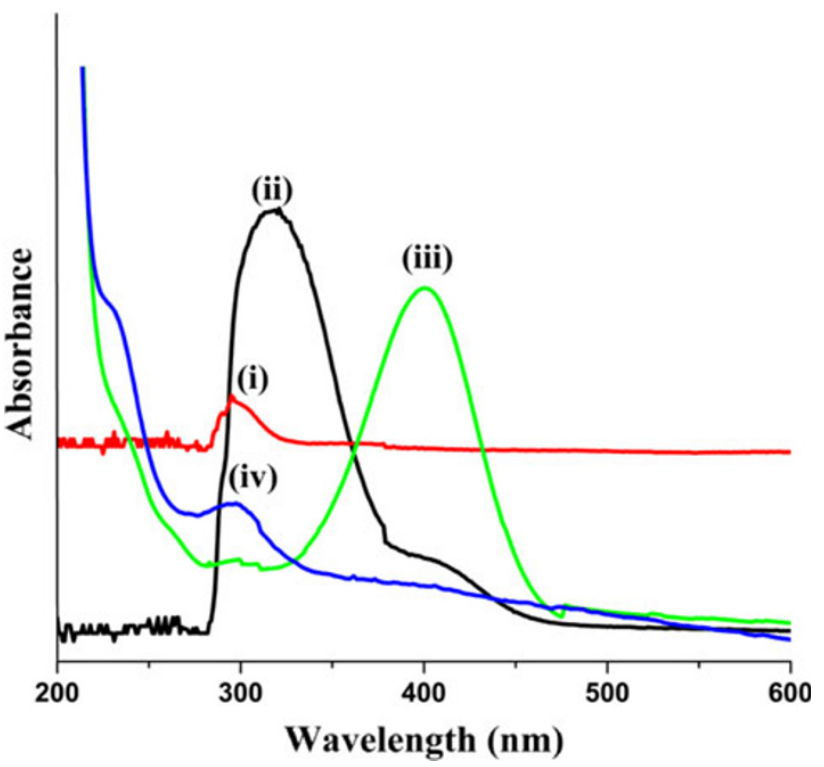

Fig. 7 UV-visible absorption spectra of aqueous solutions of (i) pure 4-aminophenol, (ii) pure 4-nitrophenol, (iii) 4-nitrophenolate ion and (iv) silver nanoparticles catalyzed product

of the silver nanoparticles, catalytic reaction starts by the transfer of electron from $\mathrm{BH}_{4}{ }^{-}$to 4-nitrophenolate ion. Thus, silver nanoparticles help in facilitating the reduction of 4-nitrophenol by lowering the activation energy of the reaction and play the role of catalyst.

Antibacterial activity studies

The silver nanoparticles synthesized by this method showed $20 \mathrm{~mm}$ and $15 \mathrm{~mm}$ inhibition zones, respectively, against E. coli and M. luteus as shown in Fig. 8, which are greater than that shown by chitosan alone. Here, the antibacterial effect of silver nanoparticles was more pronounced against Gram-negative (E. coli) than Grampositive (M. luteus) as the Gram-positive bacteria possess a thick cell wall containing high amount of peptidoglycan. In contrast, Gram-negative bacteria have two layers of cell membranes. The outer membrane comprises lipopolysaccharide, which protects it from several antibiotics, detergents and drugs that would normally damage the inner
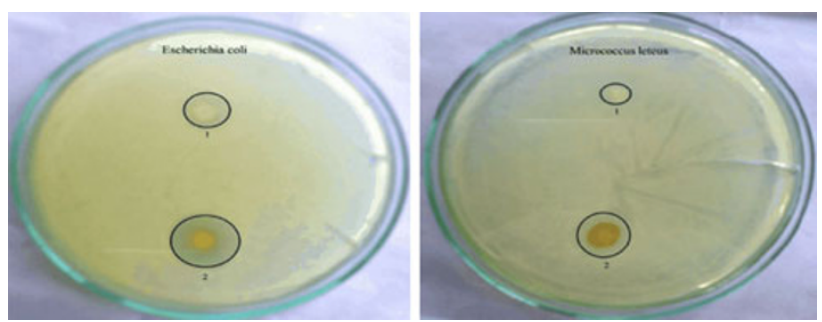

Fig. 8 Antibacterial test results for E. coli and M. leteus after 24 h of incubation. 1 chitosan 2 silver nanoparticles stabilized in chitosan 
membrane or cell wall (peptidoglycan). The outer membrane provides these bacteria with resistance to many antibacterial drugs.

\section{Conclusions}

A simple, one step green approach was developed for synthesis of silver nanoparticles using chitosan. Chitosan acted as both reducing and stabilizing agent. The silver nanoparticles that are formed are highly stable and have significant catalytic activity toward reduction of 4-nitrophenol to 4-aminophenol. These green synthesized silver nanoparticles had significant antibacterial action on E. coli and M. luteus bacteria. It was also observed that these nanoparticles showed higher antibacterial property on Gram-negative (E. coli) than Gram-positive (M. luteus) bacteria.

Open Access This article is distributed under the terms of the Creative Commons Attribution License which permits any use, distribution, and reproduction in any medium, provided the original author(s) and the source are credited.

\section{References}

Abdul kareem K, Anu kaliani A (2011) Synthesis and thermal study of octahedral silver nano-plates in polyvinyl alcohol (PVA). Arab J Chem 4:325-331

Bhui DK, Misra A (2012) Synthesis of worm like silver nanoparticles in methyl cellulose polymeric matrix and its catalytic activity. Carbohydr Polym 89:830-835

Bouazza S, Alonzo V, Hauchard D (2009) Synthesis and characterization of $\mathrm{Ag}$ nanoparticles-polyaniline composite powder material. Synth Metals 159:1612-1619

Byeon JH, Kim YW (2012) A novel polyol method to synthesize colloidal silver nanoparticles by ultrasonic irradiation. Ultrason Sonochem 19:209-215

Campelo JM, Luna D, Luque R, Marinas JM, Romero AA (2009) Sustainable preparation of supported metal nanoparticles and their applications in catalysis. Chem Sus Chem 2:18-45

Chimentao RJ, Kirm I, Medina F, Rodríguez X, Cesteros Y, Salagre $P$, Sueiras JE (2004) Different morphologies of silver nanoparticles as catalysts for the selective oxidation of styrene in the gas phase. Chem Commun (7):846-847

Debarre A, Jaffiol R, Julien C, Tchenio P, Mostafavi M (2004) Raman scattering from single $\mathrm{Ag}$ aggregates in presence of EDTA. Chem Phys Lett 386:244-247

Gong J, Mullins CB (2009) Surface science investigations of oxidative chemistry on gold. Acc Chem Res 42:1063-1073

Hettiarachchi MA, Wickramarachchi PASR (2011) Synthesis of chitosan stabilized silver nanoparticles using gamma ray irradiation and characterization. J Sci Univ Kelaniya 6:65-75

Hosseini M, Momeni MM (2010) Silver nanoparticles dispersed in polyaniline matrixes coated on titanium substrate as a novel electrode for electro-oxidation of hydrazine. J Mater Sci 45: 3304-3310

Hu B, Wang SB, Wang K, Zhang M, Yu SH (2008) Microwaveassisted rapid facile "green" synthesis of uniform silver nanoparticles: self-assembly into multilayered films and their optical properties. J Phys Chem C 112:11169-11174

Huang NM, Radiman S, Lim HN, Khiew PS, Chiu WS, Lee KH, Syahida A, Hashim R, Chia CH (2009) Gamma-ray assisted synthesis of silver nanoparticles in chitosan solution and the antibacterial properties. Chem Eng J 155:499-507

Jigar MJ, Sinha VK (2007) Ceric ammonium nitrate induced grafting of polyacrylamide onto carboxymethyl chitosan. Carbohydr Polym 67:427-435

Krishna Rao KSV, Ramasubba Reddy P, Lee YI, Kim C (2012) Synthesis and characterization of chitosan-PEG-Ag nano composites for antimicrobial application. Carbohydr Polym 87: 920-925

Kutsenko AS, Granchak VM (2009) Photochemical synthesis of silver nanoparticles in polyvinyl alcohol matrices. Theor Exp Chem $45: 313-318$

Li X, Wang J, Zhang Y, Li M, Liu J (2010) Surfactant less synthesis and the surface-enhanced Raman spectra and catalytic activity of differently shaped silver nanomaterials. Eur J Inorg Chem 2010:1806-1812

Link S, Wang ZL, El-Sayed MA (1999) Alloy formation of goldsilver nanoparticles and the dependence of the plasmon absorption on their composition. J Phys Chem B 103:3529-3533

Liu I, Sonshine DA, Shervani S, Hurt RH (2010) Controlled release of biologically active silver from nanosilver surfaces. ACS Nano 4:6903-6913

Ma GP, Yang DZ, Zhou YS, Xiao M, Kennedy JF, Nie J (2008) Preparation and characterization of water-soluble $\mathrm{N}$-alkylated chitosan. Carbohydr Polym 74:121-126

Nadagouda MN, Speth TF, Varma RS (2011) Microwave-assisted green synthesis of silver nanostructures. Acc Chem Res 44:469-478

Onishi H, Machida Y (1999) Biodegradation and distribution of water-soluble chitosan in mice. Biomaterials 20:175-182

Panigrahi S, Basu S, Praharaj S, Pande S, Jana S, Pal A, Ghosh KS, Pal T (2007) Synthesis and size-selective catalysis by supported gold nanoparticles: study on heterogeneous and homogeneous catalytic process. J Phys Chem C 111:4596-4605

Pocurull E, Marce RM, Borrull F (1996) Determination of phenolic compounds in natural waters by liquid chromatography with ultraviolet and electrochemical detection after on-line trace enrichment. J Chromatogr A 738:1-9

Pradhan N, Pal A, Pal T (2001) Catalytic reduction of aromatic nitro compounds by coinage metal nanoparticles. Langmuir 17:1800-1802

Rao YN, Banerjee D, Datta A, Das SK, Guin R, Saha A (2010) Gamma irradiation route to synthesis of highly re-dispersible natural polymer capped silver nanoparticles. Radiat Phys Chem 79:1240-1246

Shimizu K, Miyamoto Y, Satsuma A (2010) Silica-supported silver nanoparticles with surface oxygen species as a reusable catalyst for alkylation of arenes. ChemCatChem 2:84-91

Spadaro D, Barletta E, Barreca F, CurrO G, Neri F (2010) Synthesis of PMA stabilized silver nanoparticles by chemical reduction process under a two-step UV irradiation. Appl Surf Sci 256: $3812-3816$

Starowicz M, Stypula B, Banas J (2006) Electrochemical synthesis of silver nanoparticles. Electrochem Commun 8:227-230

Tan Y, Dai X, Li Y, Zhu D (2003) Preparation of gold, platinum, palladium and silver nanoparticles by the reduction of their salts with a weak reductant-potassium bitartrate. J Mater Chem 13:1069-1075

Terekhov SN, Mojzes P, Kachan SM, Mukhurov NI, Zhvavyi SP, Panarin AY, Khodasevich IA, Orlovich VA, Thorel A, Grillon F, Turpin PY (2011) A comparative study of surface-enhanced 
Raman scattering from silver-coated anodic aluminum oxide and porous silicon. J Raman Spectrosc 42:12-20

Tsujino K, Matsumura M (2005) Boring deep cylindrical nanoholes in silicon using silver nanoparticles as a catalyst. Adv Mater 17:1045-1047

Xu X, Yang Q, Wang Y, Yu H, Chen X, Jing X (2006) Biodegradable electrospun poly(L-lactide) fibers containing antibacterial silver nanoparticles. Eur Polymer J 42:2081-2087
Zhang D, Liu X, Wang X, Yang X, Lu L (2011) Optical properties of monodispersed silver nanoparticles produced via reverse micelle microemulsion. Phys B Condens Matter 406:1389-1394 